\title{
Raf Kinase Inhibitor Protein (RKIP) Deficiency Decreases Latency of Tumorigenesis and Increases Metastasis in a Murine Genetic Model of Prostate Cancer
}

June Escara-Wilke, ${ }^{1}$ Jill M. Keller, ${ }^{1}$ Kathleen M. Woods Ignatoski, ${ }^{1}$ Jinlu Dai, ${ }^{1}$ Gregory Shelley, ${ }^{1}$ Atsushi Mizokami, ${ }^{2}$ Jian Zhang, ${ }^{3}$ Miranda L Yeung, ${ }^{4}$ Kam C. Yeung, ${ }^{4}$ and Evan T. Keller ${ }^{1 *}$

\author{
'Department of Urology, University of Michigan, Ann Arbor, Michigan \\ ${ }^{2}$ Department of Urology, Kanazawa University, Kanazawa, Japan \\ ${ }^{3}$ Center for Translational Medicine, Guangxi Medical University, Nanning, China \\ ${ }^{4}$ Department of Cancer Biology and Biochemistry, University of Toledo, Toledo, Ohio
}

\begin{abstract}
BACKGROUND. Raf kinase inhibitor protein (RKIP) has been shown to act as a metastasis suppressor gene in multiple models of cancer. Loss of RKIP expression promotes invasion and metastasis in cell transplantation animal models. However, it is unknown if RKIP expression can impact the progression of cancer in an autochthonous model of cancer. The goal of this study was to determine if loss of RKIP expression in a genetic mouse model of prostate cancer (PCa) impacts metastasis.

METHODS. Endogenous RKIP expression was measured in the primary tumors and metastases of transgenic adenocarcinoma of the mouse prostate $\left(\mathrm{TRAMP}^{+}\right)$mice. RKIP knockout mice $\left(\mathrm{RKIP}^{-/-}\right)$were crossbred with $\left(\mathrm{TRAMP}^{+}\right)$mice to create $\mathrm{RKIP}^{-/-} \mathrm{TRAMP}^{+}$ mice. Mice were euthanized at 10, 20, and 30 weeks for evaluation of primary and metastatic tumor development. To determine if loss of RKIP alone promotes metastasis, RKIP was knocked down in the low metastatic LNCaP prostate cancer cell line.

RESULTS. Endogenous RKIP expression decreased in $\mathrm{TRAMP}^{+}$mice as tumors progressed. Primary tumors developed earlier in $\mathrm{RKIP}^{-/-} \mathrm{TRAMP}^{+}$compared to $\mathrm{TRAMP}^{+}$mice. At 30 weeks of age, distant metastases were identified only the $\mathrm{RKIP}^{-/-} \mathrm{TRAMP}^{+}$mice. While prostate epithelial cell proliferation rates were higher at 10 and 20 weeks in $\mathrm{RKIP}^{-/-} \mathrm{TRAMP}^{+}$ compared to $\mathrm{TRAMP}^{+}$mice, by 30 weeks there was no difference. Apoptosis rates in both groups were similar at all timepoints. Decreased RKIP expression did not impact the metastatic rate of LNCaP in an orthotopic PCa model.

CONCLUSIONS. These results demonstrate that loss of RKIP decreases latency of tumor development and promotes distant metastasis in the TRAMP mouse model in the context of a pro-metastatic background; but loss of RKIP alone is insufficient to promote metastasis. These findings suggest that in addition to its known metastasis suppressor activity, RKIP may promote tumor progression through enhancing tumor initiation. Prostate 75:292-302, 2015.

(C) 2014 Wiley Periodicals, Inc.
\end{abstract}

KEY WORDS: $\quad$ metastasis suppressor gene; LNCaP; TRAMP model

\section{INTRODUCTION}

Raf kinase inhibitor protein (RKIP), originally identified as a phosphatidylethanolamine-binding protein (PEBP), was demonstrated to inhibit Raf-1-mediated phosphorylation of MEK-1 through competitively binding to these signaling proteins [1]. The resulting inhibition of MEK-1 activation culminates in inhibition
The present address of Kathleen M. Woods Ignatoski is Department of Surgery, University of Michigan, Ann Arbor, MI 48105

${ }^{*}$ Correspondence to: Evan T. Keller, Department of Urology, University of Michigan, Rm. 5304 CCGCB, Ann Arbor, MI 48109-5940.

E-mail: etkeller@umich.edu

Received 9 July 2014; Accepted 8 September 2014

DOI 10.1002/pros.22915

Published online 18 October 2014 in Wiley Online Library

(wileyonlinelibrary.com). 
of MEK-1-mediated activation of extracellular signalregulated kinase (ERK) activation. Additional studies have shown that RKIP regulates multiple critical signaling pathways including inhibition of Stat3 [2,3] and NFкB [4]. Due to impact on so many signaling pathways, RKIP modulates many important cellular functions including spermatogenesis, immune response, and neuropeptide production (reviewed in Ref. $[5,6]$ ) and may contribute to pathological states such as Alzheimer's disease [7] and cancer [8].

Initial studies regarding RKIP's role in cancer demonstrated that it modulates apoptosis in response to chemotherapeutics in cancer cells [9-11] and serves as a metastasis suppressor gene in prostate cancer (PCa) [12]. Since these initial findings, decreased RKIP expression has been shown to play a role in multiple cancers based on clinical tissue and experimental data (reviewed in Ref. [8]). In the majority of experimental studies to determine RKIP function in cancer, RKIP expression has either been knocked down or overexpressed in cancer cell lines. While these studies have highlighted the importance of RKIP, they are limited by the use of established cancer cell lines in which the transformation to cancer has already occurred. This makes it challenging to determine the impact of RKIP loss prior to normal cells transforming to cancer cells. Understanding the role of RKIP in transformation and tumor progression can lead towards identifying important cellular pathways for identifying putative therapeutic targets. Accordingly, the goal of this study was to determine if RKIP deficiency prior to the onset of cancer promotes PCa progression.

\section{MATERIALS AND METHODS}

\section{Animals and PCR Genotyping}

Parental RKIP knockout mice created in a C57Bl/6 background were previously described [13]. C57Bl/6 heterozygous TRAMP females were purchased from Jackson Labs (Bar Harbor, ME). RKIP knockout males were bred with TRAMP + females. RKIP+/+TRAMP+, $\mathrm{RKIP}^{-/-}$TRAMP + , and RKIP ${ }^{-/}$TRAMP - were generated through successive backcross and sibling breeding. Normal mice (genotyped to ensure they did not contain the genetic mutations) were derived from the knockout breeding colony. Mouse handling and breeding were performed following the guidelines set by UCUCA of the University of Michigan. PCR genotyping was performed with GoTaq DNA Polymerase (Promega Corp, Madison, WI) using 50ng of DNA template and the RKIP primers: RKIP WT FORgagccctggccggtctccettgtcccaaacttt (final $0.2 \mu \mathrm{M}$ ), RKIP WT REV gacttccgtgtccggatgatagatagcctctcc $(0.1 \mu \mathrm{M})$ and RKIP KO REV (BGEOR2) ccaaaagggtctttgagcaccagaggacatccg $(0.1 \mu \mathrm{M})$ [5]. T-antigen primers were designed to multiplex PCR with $\beta$-globin as internal housekeeping gene marker: Probasin SV40 Large TAg FOR - ccggtcgaccggaagcttccacaagtgcattta; TAg REV-aggcattccaccactgctcccattcatc $\beta$-globin 2589FORgccaatctgctcacacaggata; $\beta$-globin 3128REV-catgcagcttgtcacagtgga. RKIP and TAg-globin PCR was performed at $60^{\circ} \mathrm{C}$ annealing temperature. All primers were synthesized by InVitrogen (Life Technologies, Inc., Carlsbad, CA).

\section{RT-PCR, qPCR}

Tissues were homogenized in Trizol reagent (Life Technologies, Inc.) with a Qiagen TissueLyzer and total RNA was extracted using RNeasy Mini Kit (Qiagen, Hilden, Germany). cDNA synthesis was performed using random hexamers or oligo-dT and MuLV RT (Promega) or using miScript cDNA synthesis kit (Qiagen). One out of ten dilution of the cDNAs were used for non-quantitative PCR. For RKIP RTPCR, the following primers were used: RKIP exon 1 FOR primer-gagctgggcaaagtgctaac, RKIP exon 2 REV primer-gtctgtgaggaccagggtgt. SV40 large T-antigen mRNAs were amplified using TAg qPCR primers, TAg FOR - gtcagtgaggtccagatacctacc, TAg REV—caggcactcctttcaagaccta. LightCycler Probe Master was used for qPCR reaction using $1 / 50$ dilution of the cDNA. Probe \#3 $(0.1 \mu \mathrm{M})$ of the Universal Probe Library (Roche Applied Sciences, Basel, Switzerland) was used for RKIP with the following designed primers: mouse RKIP probe left primer tcctcacagaccccgatg, mouse RKIP probe right primer, agtggtgccactccetga. Probe \#63 of the UPL was used for mouse $\beta$-actin with the UPL-recommended primers. For T-antigen amplification, Light Cycler SYBR Green Master was used with the T-antigen $\mathrm{GPCR}$ primers above. Mouse $18 \mathrm{~S}$ rRNA was used as reference gene. qPCR was performed in a Roche LC480 machine using Roche Light Cycler 480 Probes Master reagent in 384 well plates. All reactions were performed in triplicate and repeated three times.

\section{Antibodies for Western and IHC}

Thirty micrograms of protein were loaded into $10 \%$ gel for protein transfer and antibody development. RKIP was visualized using Rabbit anti-RKIP (N-term) from InVitrogen (Life Technologies, Inc.) or mouse anti-RKIP MAb from Zymed Laboratories (San Francisco, CA). The SCBT (Santa Cruz Biotechnology, Inc., Santa Cruz, CA) antibody H17 Goat polyclonal anti-RKIP was used for RKIP IHC. T-antigen antibody PAb 101 from BD Pharmingen (BD BioSciences, San Jose, CA) or rabbit anti-SV40 $\mathrm{T} \mathrm{Ag}$ antibody V-300 from SCBT were utilized for western and IHC. Western 
development was performed using the SuperSignal West Dura Extended Duration Substrate or the SuperSignal West Pico Chemiluminescent Substrate (Thermo Fisher Scientific, Waltham, MA). Bands were measured using densitometry.

\section{Longitudinal Study}

All animal studies were approved by the University of Michigan Animal Use and Care Committee. Double hybrid males RKIP+/+TRAMP+ $(\mathrm{n}=38), \mathrm{RKIP}^{-/-}$ TRAMP $^{-} \quad(\mathrm{n}=34)$ and RKIP ${ }^{-/}$TRAMP $+(\mathrm{n}=43)$ were randomly assigned into cohorts for sacrifice at 10 , 20 , or 30 weeks. Total mice numbers were based on the available male mice at the initiation of the study for each genotype and power analysis. At a minimum of 10 mice per group per time point there was $>90 \%$ power to detect a difference of $60 \%$ between groups at $P<0.05$. At sacrifice, the dorsolateral and ventral lobes of the prostate or the prostate tumor were dissected along with the seminal vesicle, major organs (lungs, liver, heart, kidney, brain, and spleen) and measurable lymph nodes. Tissues were weighed, prostate tumors were measured, and macroscopic lesions (suspected tumor metastasis sites) were recorded. Tissues were fixed in $10 \%(\mathrm{v} / \mathrm{v})$ phosphate-buffered formalin for 24$48 \mathrm{hr}$ at $4^{\circ} \mathrm{C}$ then transferred to cold $70 \%$ ethanol. Paraffin imbedded tissues were sectioned at $5 \mu \mathrm{m}$ thick and mounted on Plus slides. Sections were stained with H\&E, RKIP antibody or T-antigen antibody.

\section{Orthotopic Tumor Studies}

LNCaP cells or C4-2B cells [14] $\left(10^{5}\right.$ cells) with various modulations of RKIP were injected into dorsolateral lobe of prostates of SCID mice $(n=10 /$ group) and allowed to form tumors for 12 weeks at which time mice were euthanized. At necropsy, PCa tumors and lungs were removed, fixed in $10 \%$ normal buffered formalin, and transferred to $70 \% \mathrm{EtOH}$. After $24 \mathrm{hr}$, the samples were paraffin embedded. Each sample was sectioned four times at $300 \mu \mathrm{m}$ intervals and stained with hematoxylin and eosin and prostate specific antigen (PSA).

\section{Boyden Chamber Assays}

LNCaP cells $\left(2.5 \times 10^{4}\right)$ were plated in triplicate in Boyden Chamber wells and control wells containing just membrane (BD Biosciences, Franklin Lakes, NJ). Medium with 5\% FBS was placed in the upper chamber with the cells and medium with $10 \%$ FBS was placed in the lower chamber. Plates were incubated for $24 \mathrm{hr}$ at $37^{\circ} \mathrm{C}$. Cells were detected by HEMA 3 stain (Catalog \# 122-911, Fisher Scientific, Kalamazoo, MI) and quantified using microscopic detection. Invasive ability was defined as proportion of cells penetrating coated wells divided by number of cells migrating through uncoated membranes. Assays were performed in triplicate and repeated at least twice.

\section{Statistical Analysis}

One-way ANOVA analysis was used to determine statistical significance with or without a post hoc test for most results. Proportion of Ki-67 was analyzed using a linear mixed model with repeated measures to account for the many areas examined within each mouse. Pairwise comparisons between genotypes were tested for each necropsy time within the model. Survival time for each necropsy group was analyzed using product limit estimates from the Kaplan-Meier method. The log-rank test was used with Tukey-Kramer adjustments for multiple pairwise comparisons of survival times between genotypes. GraphPad PRISM and SAS 9.2 (SAS Institute, Cary, NC) were used for analysis.

\section{RESULTS}

\section{RKIP Expression Declines in TRAMP Mice During Progression of Prostatic Disease From PIN to Metastasis}

Loss of RKIP expression is associated with increased metastasis [8]. In clinical PCa tissue, RKIP expression decrease in primary tumors compared to non-cancer prostate and further decreased in metastases compared to primary tumors [15]. These results suggest that as PCa progresses, RKIP expression declines; however, as these tissues are taken from different patients and at different time points; it is possible that this association is not reflective of the pathogenesis of $\mathrm{PCa}$. To explore if RKIP declines as PCa progresses, we evaluated the expression of RKIP in the prostates of the transgenic adenocarcinoma of the mouse prostate (TRAMP) mouse model of PCa. Use of a well-defined model of PCa enables evaluation of RKIP expression with consistency between tumors. RKIP expression declined as PCa progressed with RKIP expression in primary tumors lower than that in normal prostate and RKIP expression in metastases was lower than that that of primary tumors (Fig. 1a). The decline of RKIP expression was found in multiple metastatic sites including lymph node, lung, and liver (Fig. 1b).

\section{Generation of RKIP Defıcient TRAMP Mice}

The finding that RKIP expression declined as PCa tumors progressed in TRAMP mice is consistent with the concept that loss of RKIP is a driver of tumor 


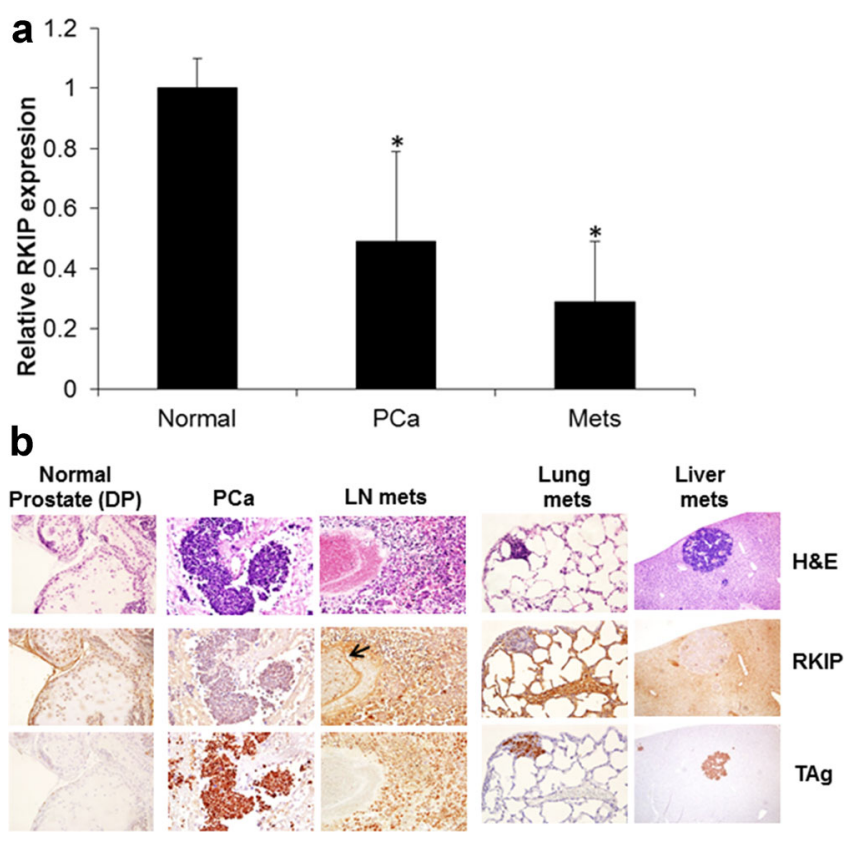

Fig. I. RKIP expression decreases as prostate cancer progresses to metastasis in TRAMP mice. a: Endogenous levels of RKIP mRNA in normal prostate, prostate cancer (PCa) and organ metastasis (Mets) were quantified using real-time quantitative PCR (qRT-PCR). $\beta$-Actin was used to normalize for sample loading. ${ }^{*} P<0.05$ versus Normal. b: Immunohistochemical staining for the indicated target protein $(400 \times$ magnification).

progression. However, it is also possible that loss of RKIP expression is just a passenger and has no impact on PCa progression. To delineate if RKIP has a role in PCa progression, mice with the rkip gene knocked out $\left(\mathrm{RKIP}^{-/}{ }^{-}\right)$[13] were bred with TRAMP mice to generate TRAMP mice deficient in RKIP expression $\left(\mathrm{RKIP}^{-/-} \mathrm{TRAMP}^{+}\right)$. The genotypes of mice were confirmed using DNA PCR genotyping of tail clips (not shown). To further ensure that prostate RKIP and TAg expression reflected the genotypes, we evaluated prostate RKIP and TAg mRNA and protein expression. RKIP mRNA and protein expression were absent; whereas, TAg mRNA and protein expression was present in lysates and intact tissues of the prostates of RKIP $^{-/}{ }^{-} \mathrm{TRAMP}^{+}$mice (Fig. 2). The overexpression of $\mathrm{TAg}$ in the prostate accounts for the occurrence of $\mathrm{PCa}$ in the TRAMP mice. Thus, it is plausible that modulation of TAg expression could impact PCa development or progression. To ensure any phenotypes we observed were not due to RKIP-mediated modulation of $\mathrm{TAg}$, we measured TAg mRNA expression in the different prostate lobes of the mice. No difference in TAg expression was observed among the different groups of mice and, as expected, the TAg expression was localized to the prostate (Fig. 2d). Taken together, these findings indicate that $\mathrm{RKIP}^{-/}$TRAMP $^{+}$mice have been successfully created and that phenotypes mediated by loss of RKIP expression are not due to changes in TAg expression.

\section{Loss of RKIP Promotes Primary PCa Growth in TRAMP Mice}

In order to determine the impact of loss of RKIP expression on PCa progression, we established colonies of $\mathrm{RKIP}^{-/-} \mathrm{TRAMP}^{+}$, $\mathrm{RKIP}^{-/-} \mathrm{TRAMP}^{-}$, and $\mathrm{RKIP}^{+/+} \mathrm{TRAMP}^{+}$, and euthanized mice at 10,20 , or 30 weeks old to evaluate PCa progression. There was no significant difference in the average weights of the major organs at all timepoints (not shown). In contrast, while there were no tumors in the $\mathrm{RKIP}^{-/}{ }^{-} \mathrm{TRAMP}^{-}$ mice, tumors developed in both the $\mathrm{RKIP}^{+/+} \mathrm{TRAMP}^{+}$ and the $\mathrm{RKIP}^{-/}{ }^{-} \mathrm{TRAMP}^{+}$mice with tumors in the latter group being larger at 30 weeks (Fig. 3a). The incidence of primary prostate tumor is summarized in Table I and pathology is depicted in Figure $3 \mathrm{~b}$. At 20 weeks, almost $60 \%$ of $\mathrm{RKIP}^{-/-} \mathrm{TRAMP}^{+}$mice had PCa; whereas, none of the RKIP $^{+/+}$TRAMP $^{+}$had measurable PCa. At 30 weeks, approximately $90 \%$ of the $\mathrm{RKIP}^{-/-}$TRAMP $^{+}$mice had PCa; whereas, approximately $33 \%$ of the $\mathrm{RKIP}^{+/+} \mathrm{TRAMP}^{+}$mice had measureable PCa. The remaining $\mathrm{RKIP}^{+/+} \mathrm{TRAMP}^{+}$ mice exhibited PIN histology in their prostate and 75\% demonstrated epithelial-stromal tumor of the SV. $\mathrm{RKIP}^{-/}{ }^{-} \mathrm{TRAMP}^{+}$mice at 30 weeks exhibit undifferentiated PCa with no observable luminal epithelial cells. In $\mathrm{RKIP}^{-/}{ }^{-} \mathrm{TRAMP}^{-}$mice, no tumors developed. Taken together these data suggest that RKIP deficiency, while insufficient as a solitary event to promote PCa initiation, decreases latency for prostate tumor initiation and progression in TRAMP mice.

\section{RKIP Deficiency Increases Incidence of Metastasis}

To determine if RKIP expression impacts the incidence of metastasis, metastases were scored both by macroscopic observation during necropsy and by microscopic analysis of organs. Lymph node metastases were not identified in any group until 30 weeks of age (Table II). The number of mice with lymph node metastases were much higher in $\mathrm{RKIP}^{-/-}$TRAMP $^{+}$ mice compared to $\mathrm{RKIP}^{+}{ }^{+} \mathrm{TRAMP}^{+}$mice $(84 \%$ vs. $8 \%$, respectively). Only $\mathrm{RKIP}^{-/-} \mathrm{TRAMP}^{+}$mice developed metastases by 30 weeks $(53 \%)$ with one $\mathrm{RKIP}^{-/-}$ TRAMP $^{+}$mouse demonstrating organ metastasis at 20 weeks (Table III). RKIP ${ }^{-1}{ }^{-} \mathrm{TRAMP}^{+}$mice had between 0 and 6 metastases per mouse (average of 0.84 metastases per mouse) compared to $\mathrm{RKIP}^{+/+}$ TRAMP $^{+}$mice which had $0-2$ in mice (average of 0.08 per mouse) (Fig. 4a). Although lymph node metastases far outnumbered individual organ metastases, the 
a R+T+ R-T- R-T+

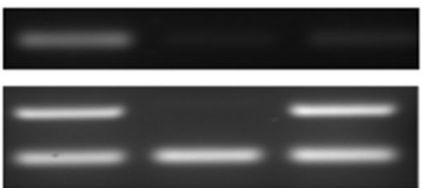

RKIP

TAg

$\beta$-actin RKIP

b

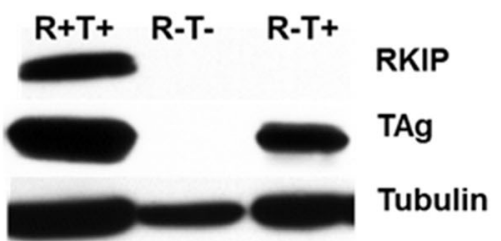

C

\section{RKIP}

RKIP+/+

TRAMP+
RKIP-/-

TRAMP-
RKIP-/-

TRAMP+
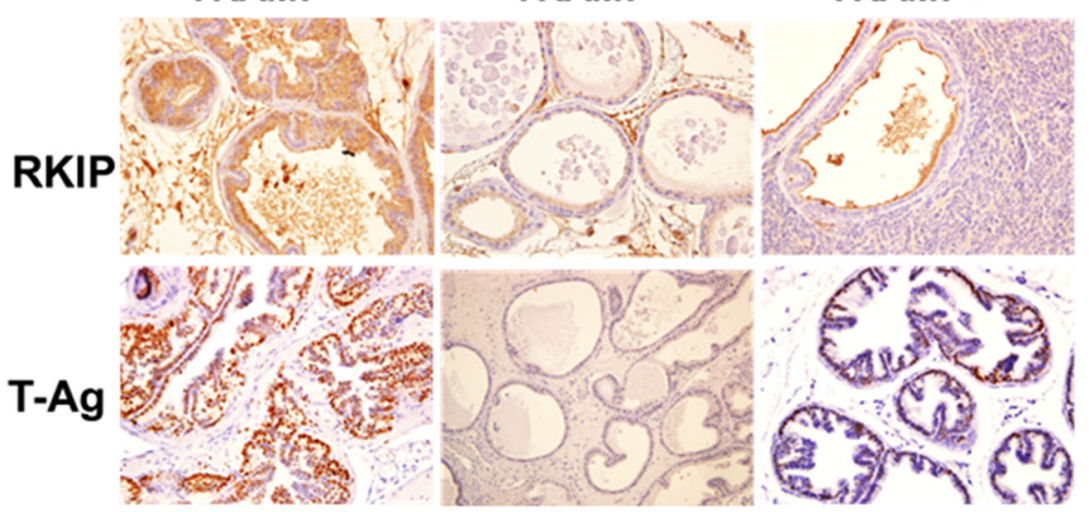

d

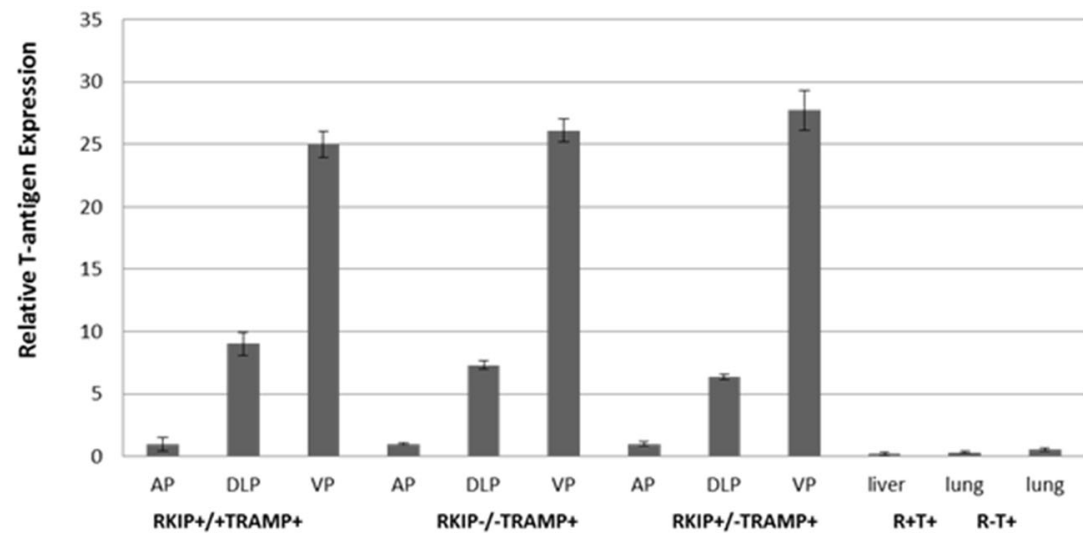

Fig. 2. Validation of creating $\mathrm{RKIP}^{-1-} \mathrm{TRAMP}^{+}$mice. Total RNA and protein was collected from prostates of $\mathrm{RKIP}^{-1-} \mathrm{TRAMP}^{+}\left(\mathrm{R}^{-} \mathrm{T}^{+}\right)$, RKIP $^{-1-}$ TRAMP $^{-}\left(\mathrm{R}^{-} \mathrm{T}^{-}\right)$, or $\mathrm{RKIP}^{+/+} \mathrm{TRAMP}^{+}\left(\mathrm{R}^{+} \mathrm{T}^{+}\right)$mice and subjected to (a) PCR and (b) immunoblot for RKIP and T-antigen (TAg). c: Prostate tissue was collected from mice with the indicated genotype and subjected to immunohistochemistry for RKIP and TAg $(400 \times)$. d: Total RNA derived from the anterior prostate (AP), dorsolateral prostate (DLP) and ventral prostate (VP) lobes and liver and lung from mice with the indicated genotype was subjected to real-time quantitative PCR forTAg expression.

a

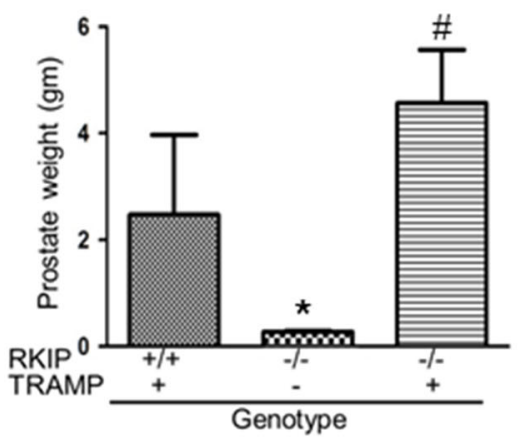

b

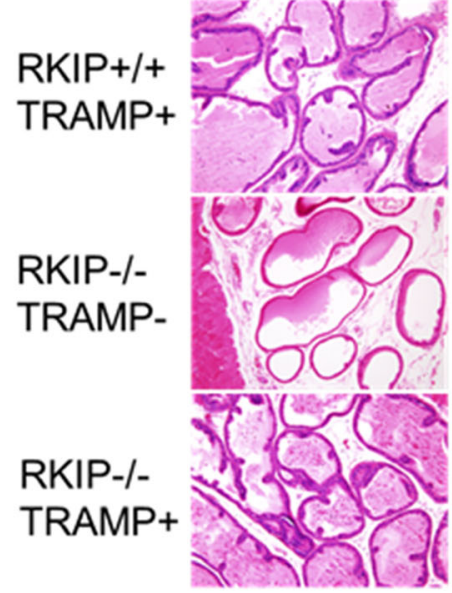

10 Wks

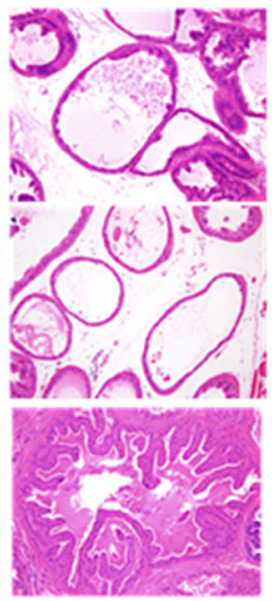

20 Wks

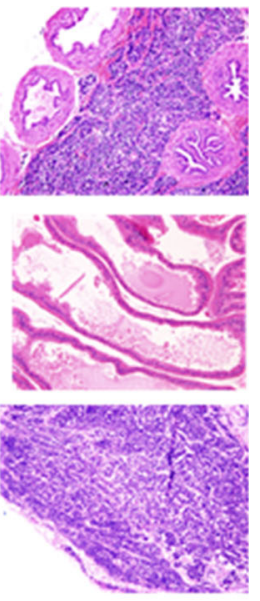

30 wks

Fig. 3. Loss of RKIP promotes prostate tumor growth in TRAMP mice. a: Prostates, including tumor when present, were weighed at 30 weeks of age. ${ }^{* P}<0.05$ versus either TRAMP+ group; ${ }^{\#} P<0.05$ versus RKIP $^{+/+} /$Tramp $^{+}$. b: Prostate tissues were collected at the indicated times and subjected to histology using hematoxylin and eosin staining. 
TABLE I. Incidence of Mice With PrimaryTumor (Percent)

\begin{tabular}{lclc}
\hline Genotype & 10 weeks & 20 weeks & 30 weeks \\
\hline RKIP+/+ TRAMP+ & $0 / 10(0)$ & $0 / 16(0)$ & $4 / 12(33.3)$ \\
RKIP-/- TRAMP- & $0 / 10(0)$ & $0 / 10(0)$ & $0 / 14(0)$ \\
RKIP-/- TRAMP+ & $0 / 12(0)$ & $7 / 12(58)$ & $17 / 19(89.5)$ \\
\hline
\end{tabular}

organ metastases were distributed relatively evenly among multiple sites in the RKIP $^{-/-}$TRAMP $^{+}$ mice (Fig. $4 b, c)$. With the exception of enlarged periprostatic lymph nodes and grossly visible liver metastases, the remaining metastases were of a microscopic nature.

\section{RKIP Impacts Tumor Growth and Proliferation}

To determine if RKIP deficiency impacts tumor growth through altering proliferation and/or apoptosis we evaluated tumor tissues for Ki67, a marker of proliferation and for DNA strand breaks (Apoptag), as an index of apoptosis. $\mathrm{RKIP}^{-/-} \mathrm{TRAMP}^{+}$mice exhibited higher proliferation rates than $\mathrm{RKIP}^{+/+} \mathrm{TRAMP}^{+}$ mice at 10 and 20 weeks; however, by 30 weeks the two groups had similar proliferation rates (Fig. 5a,b). There was no difference in the apoptotic rate between the groups (not shown). RKIP inhibits Raf kinase-mediated activation of MEK and its downstream target ERK. To confirm that loss of RKIP expression translated to increased ERK activation in TRAMP mouse prostates, we measured phospho-ERK. Phospho-ERK was increased in the prostate tumors of $\mathrm{RKIP}^{-/-} \mathrm{TRAMP}^{+}$mice compared to those of RKIP $^{+/+}$TRAMP ${ }^{+}$mice (Fig. 5c).

\section{Decreased RKIP Expression Alone Is Insufficient to Promote Metastasis in LNCaP Prostate Cancer Cells}

It has been previously demonstrated that reexpression of RKIP alone is sufficient to inhibit metastasis in several cancer types including prostate cancer cells [12] and breast cancer cells [4]. Further-

\begin{tabular}{|c|c|c|c|}
\hline Genotype & 10 weeks & 20 weeks & 30 weeks \\
\hline $\mathrm{RKIP}+/+$ TRAMP + & $0 / 10(0)$ & $0 / 16(0)$ & $1 / 12(8)$ \\
\hline RKIP-/ - TRAMP- & $0 / 10(0)$ & $0 / 10(0)$ & 0/14 (0) \\
\hline RKIP-/ - TRAMP+ & $0 / 12(0)$ & $0 / 12(0)$ & $16 / 19(84)$ \\
\hline
\end{tabular}

TABLE III. Incidence of Mice With Organ Metastasis (Percent)

\begin{tabular}{lccc}
\hline Genotype & 10 weeks & 20 weeks & 30 weeks \\
\hline RKIP+/+ TRAMP+ & $0 / 10(0)$ & $0 / 16(0)$ & $0 / 12(0)$ \\
RKIP-/- TRAMP- & $0 / 10(0)$ & $0 / 10(0)$ & $0 / 14(0)$ \\
RKIP-/- TRAMP+ & $0 / 12(0)$ & $1 / 12(8)$ & $10 / 19(53)$ \\
\hline
\end{tabular}

more, it has been shown that knockdown of RKIP promotes invasion in both prostate cancer cells [12] and breast cancer cells [4] in vitro. However, it is unknown if decreased RKIP expression alone is sufficient to increase metastasis. The findings of this current report showing that RKIP knockout promotes metastasis in TRAMP mice suggests that loss of RKIP expression alone can promote metastasis. However, it is challenging to eliminate the observed early induction of tumor growth as a mechanism that contributes to the increased metastatic rate in the $\mathrm{RKIP}^{-1-}$ TRAMP $^{+}$mice as opposed to an impact on metastatic activity itself. Accordingly, to determine if loss of RKIP is sufficient to promote metastasis, we knocked down RKIP expression in the low metastatic LNCaP cell line to determine the impact on metastatic rate. In addition, we transduced LNCaP cells with both empty vector and RKIP overexpression vector as controls. RKIP was efficiently knocked down $(\sim 80 \%)$ in the $\mathrm{LNCaP}$ cell line (Fig. 6a). Modulation of RKIP had no impact on cell growth rate in vitro (Fig. 6b). However, knockdown of RKIP increased LNCaP's invasive ability; whereas overexpression of RKIP decreased its invasive ability (Fig. 6c). To evaluate the impact of modulated RKIP expression on LNCaP cells in vivo, the transduced cells were injected into the dorsolateral prostate lobes of mice, and after 12 weeks, mice were euthanized at which time prostate tumors were weighed and the body examined for metastases. There was no difference in tumor weight among the LNCaP cell with modulation of RKIP expression (Fig. 6d). Gross metastases were only identified in lungs, as previously described [12], accordingly we quantified lung metastases. Modulation of RKIP expression had no impact on number of metastases (Fig. 6e). Taken together, these data indicate that decreased RKIP expression alone is insufficient to increased metastasis in LNCaP prostate cancer cells. To determine if loss of RKIP could enhance metastatic rate in a cell line with a high metastatic phenotype, we increased and decreased RKIP expression in C4-2B cells (Supplemental Fig. S1a), which are a metastatic variant of LNCaP cells [14], and injected them orthotopically into mice. At 12 weeks of tumor growth, mice were euthanized and examined for lung metastases. Similar to LNCaP cells, 
a

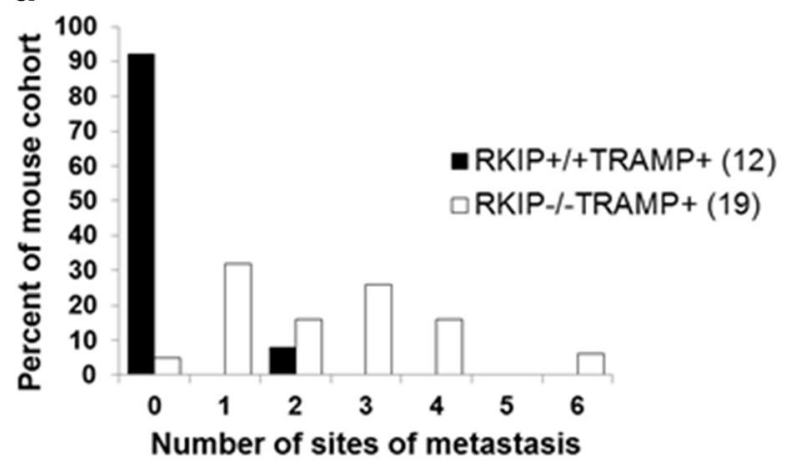

b

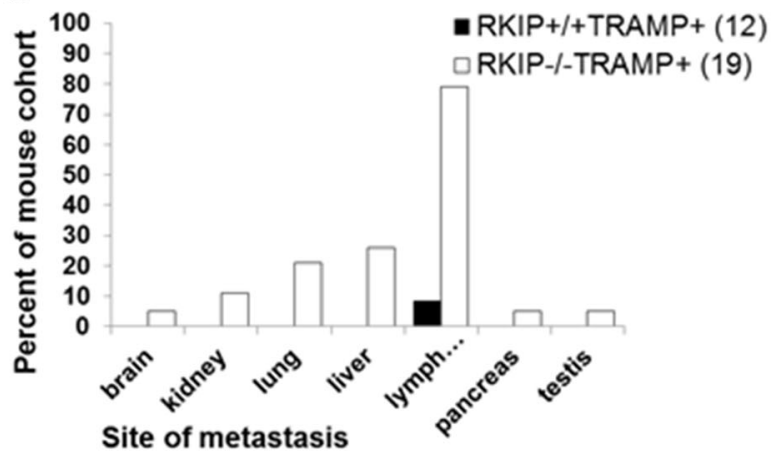

C
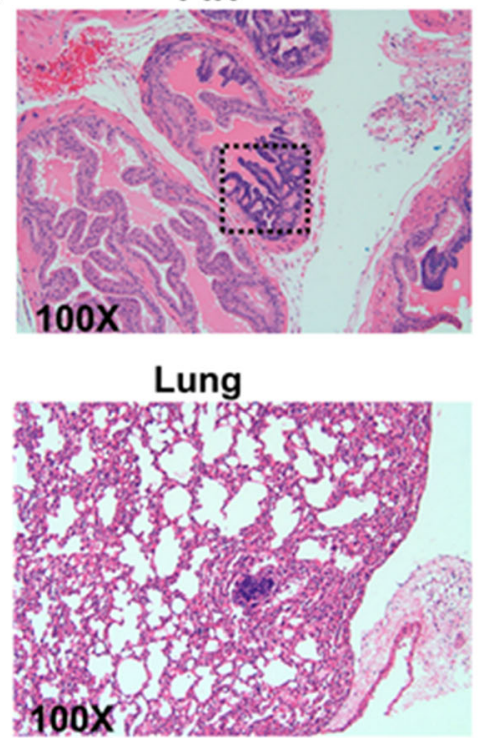

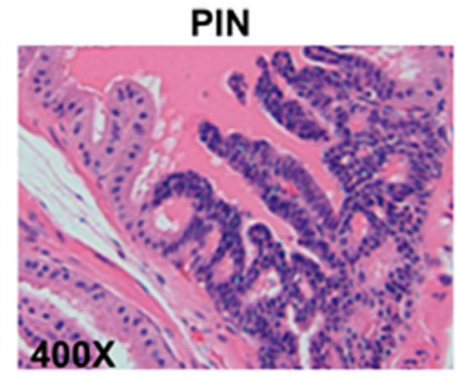

Liver

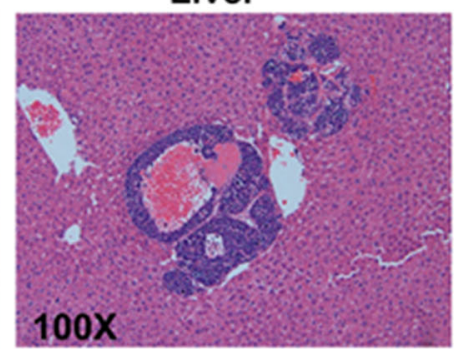

Primary prostate tumor

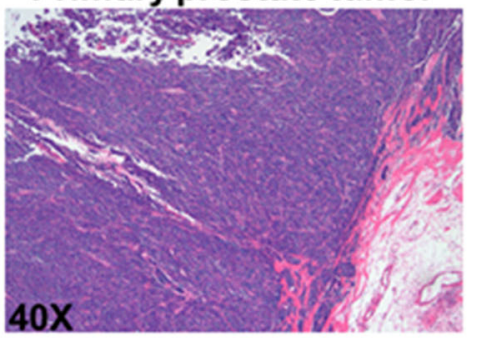

Brain

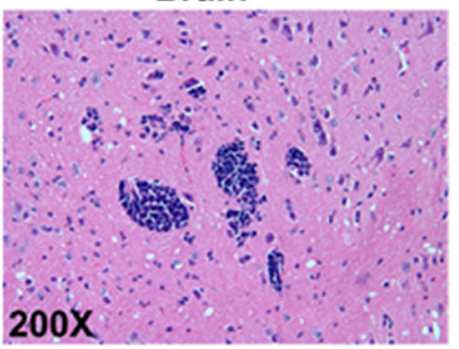

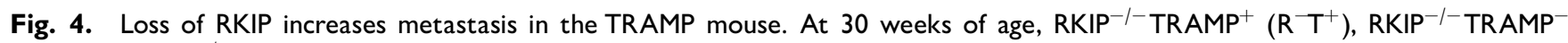
$\left(R^{-} T^{-}\right)$, or $R K I P^{+/+}$TRAMP ${ }^{+}\left(R^{+} T^{+}\right)$mice were subjected to necropsy. Prostate, brain, lung, liver, kidney, pancreas, testes were examined grossly or histologically (at least 10 sections per tissue) for evidence of tumor. $\operatorname{RKIP}^{-1-}$ TRAMP $^{-}\left(\mathrm{R}^{-} \mathrm{T}^{-}\right)$did not develop any tumor and is not depicted in this figure. $\mathbf{a}$ : the percent of mice for each genotype delineated by number of metastases is plotted. $\mathbf{b}$ : the percent of mice for each genotype delineated by metastatic site is plotted. c: representative images of prostate and metastases (PIN, prostate intraepithelial neoplasia). Hematoxylin and eosin staining.

modulation of RKIP expression in C4-2B cells had no impact on cell growth rate in vitro or in vivo (Supplemental Fig. S1b,c). In contrast to LNCaP cells, overexpression of RKIP decreased C4-2B's metastatic rate; whereas, knockdown or RKIP increased their metastatic rate (Fig. 6f). These results, in conjunction with the LNCaP results, indicate that decreased RKIP expression can enhance metastasis in pro-metastatic background, but decreased RKIP alone is insufficient to promote metastasis.

\section{DISCUSSION}

RKIP has been shown to have metastasis suppressor activity in several cancer types. The definition of a metastasis suppressor is that it inhibits components of the metastatic cascade without an impact on primary tumor growth [16,17]. Consistent with this definition, restoring expression of RKIP was shown to decrease metastasis, yet have no impact on primary tumor growth in murine models of PCa [12] and breast cancer [18]. In spite of the large body of evidence that RKIP suppresses metastasis, the mechanisms through which it achieves that are not well-defined. The results presented in this study are the first to provide direct evidence that decreased RKIP expression decreases latency of PCa tumor development and promote metastasis in an autochthonous model of cancer.

The TRAMP mouse model is a commonly used mouse model to study PCa in mice [19-21]. The 

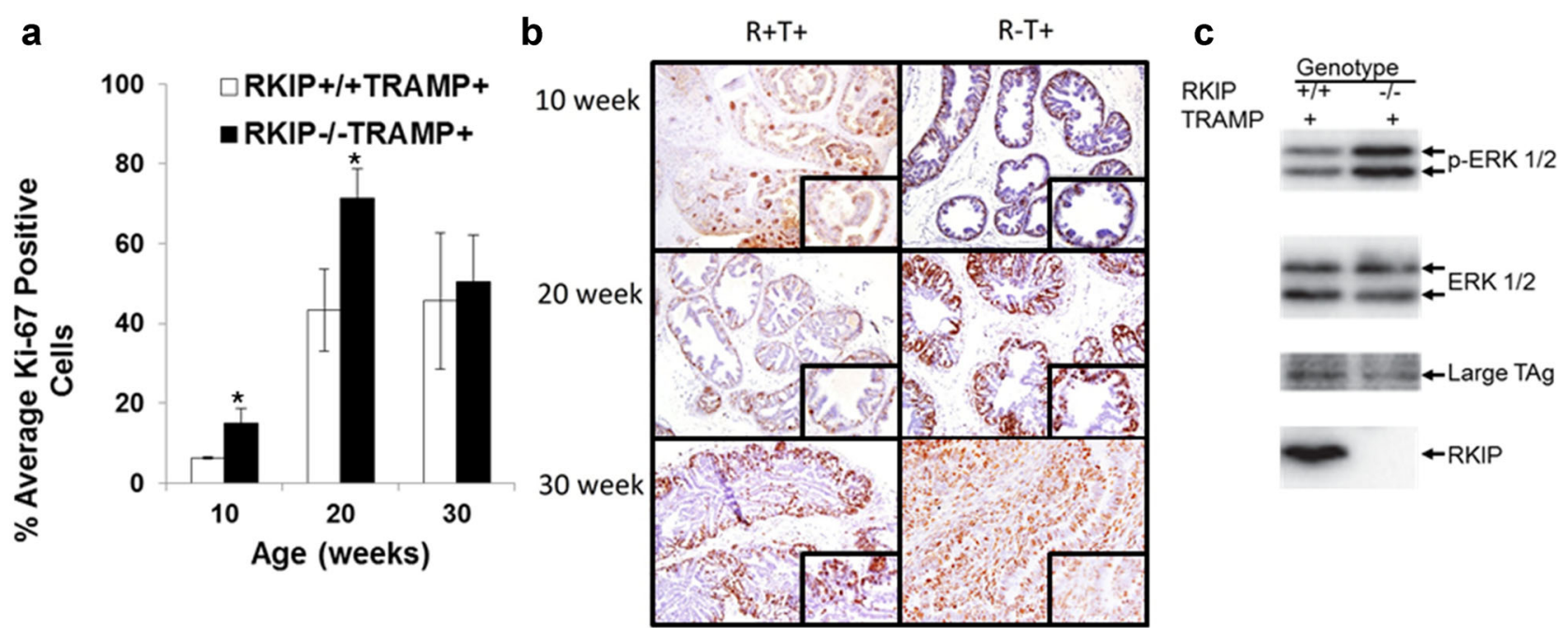

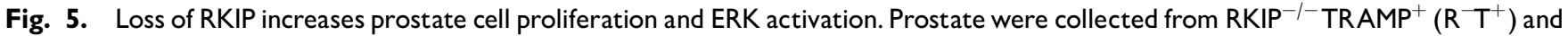
RKIP $^{+/+}$TRAMP $^{+}\left(\mathrm{R}^{+} \mathrm{T}^{+}\right)$and subjected to immunohistochemistry for Ki- 67 at the indicated timepoints. a: One hundred cells in 10 random fields were counted to generate the $\% \mathrm{Ki} 67$ positive cells per mouse and results are plotted. ${ }^{*} P<0.05$ versus $\mathrm{RKIP}^{+/+} \mathrm{TRAMP}^{+}$for the same time point. b: representative Ki67 immunohistochemistry. c: Prostate tumors were collected at 30 weeks from the indicated genotypes of mice. Total protein was harvested and subjected to immunoblot for phospho-ERKI/2, ERKI/2,TAg, and RKIP.

prostate lobes of male TRAMP mice undergo a fairly well-defined progressive development of $\mathrm{PCa}$ mimicking certain aspects of human prostate pathology beginning with PIN through distant metastasis with a high penetrance. As with any mouse model of human disease, there are limitations of the TRAMP model including the preponderance of neuroendocrine phenotype of $\mathrm{PCa}$ [22] which represents a small population of PCa patients [23]. We initially set out to use the TRAMP model to obtain in vivo validation of the metastasis suppressor function of RKIP in an autochthonous model of PCa. Our strategy was to generate RKIP-deficient-TRAMP mice to test the hypothesis that RKIP deficiency will increase the incidence of metastasis in TRAMP mice. As hypothesized, RKIP deficiency led to increased metastasis; however, unexpectedly, we identified that RKIP knockout also decreased latency for the appearance of neoplastic prostate changes. These findings appear to conflict with the earlier observations that loss of RKIP expression promotes metastasis independent of an impact on tumor growth suggesting that altered kinetics of progression results in the apparent increase in metastasis. It is also possible that the tumors initiate earlier in the context of RKIP deficiency, but grow at the same rate as in the RKIP intact state. In this situation; although growth rates are similar, at any particular time point the RKIP-deficient tumors will be larger than the RKIP-intact tumors due to the RKIPdeficient tumors starting growth at an earlier time point.
There is a preponderance of evidence in multiple tumor types that loss of RKIP expression promotes metastasis, in part, through enhancing invasion [2,18,24-26]. The mechanisms through which loss of RKIP promotes invasion include increased activity of NFкB [4], through modulation of let-7-mediated chromatin remodeling [18] and increased activity of STAT3 [2]. These activities have the potential to increase metastasis independent of an impact on cell growth as would be expected for loss of metastasis suppressor activity. The decreased latency on tumor initiation we observed in the RKIP-deficient state also provides a mechanism that could contribute to the increased metastasis observed in these animals compared to RKIP-intact animals. Specifically, the development of cells with metastatic capability may be dependent on epigenetic and genetic events that occur as the tumor grows $[27,28]$. The earlier initiation of tumor growth in the RKIP-deficient state allows for both (1) more time for pro-metastatic molecular events to occur and (2) an increasing number of cancer cells being present (i.e., more target cells). Overall, these events would result in more opportunities for development of cells with metastatic ability, including the increased invasiveness induced by loss of RKIP.

Tumor growth culminates from a balance between cell proliferation and apoptosis. Decreased RKIP expression has been shown to inhibit chemotherapyinduced apoptosis $[9,11,29]$. In our study, there was no impact on endogenous apoptosis in the prostate tissue or the prostate tumors. Together, these observations 

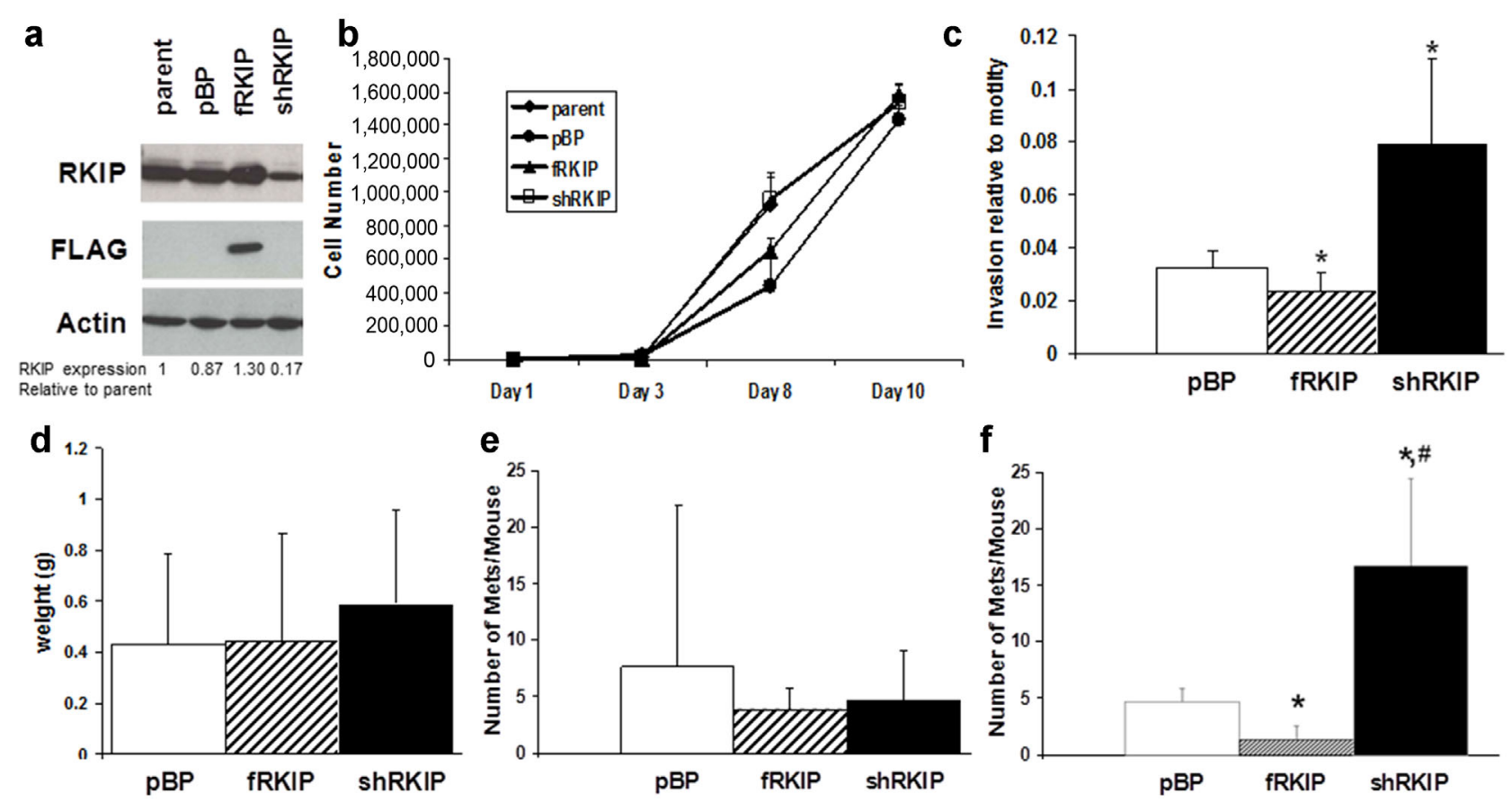

Fig. 6. Decreased RKIP expression is insufficient to increase metastatic rate of LNCaP prostate cancer cells. a: LNCaP cells were transduced with empty vector ( $\mathrm{PBP}$ ) or constructs to overexpress FLAG-RKIP (fRKIP) or knockdown RKIP (shRKIP) and selected with puromycin to create stable cell lines. Total protein was collected and subjected to immunoblot for RKIPor FLAG. Bands were measured using densitometry. b: Cells were plated equally and counted for a plating efficiency on day I and counted on days 3, 8, and I0 after plating. c: LNCaP cells were plated in a modified Boyden chamber assay. Invasive ability was defined as proportion of cells invading through the coated membranes divided by number of cells migrating through uncoated membranes. ${ }^{*} P<$ versus $\mathrm{PBP}$. d,e: $\mathrm{LNCaP}$ cells $\left(10^{5}\right.$ cells) with the indicated modulation of RKIP were injected into dorsolateral lobe of prostates of SCID mice $(n=10 /$ group $)$ and allowed to form tumors for 12 weeks at which time mice were euthanized. d: Prostate tumors were removed and weighed. e: Lungs were excised, and each lung was sectioned four times at $300 \mu \mathrm{m}$ intervals. Sections were stained with prostate specific antigen to identify metastases. Metastases were counted in all four sections of one sample and averaged. Data are reported as the average metastases per sample for 10 mice. $f: C 4-2 B$ cells $\left(10^{5}\right.$ cells) with the indicated modulation of RKIP (i.e., empty vector (pBP), overexpression ( $f R K I P)$ or knockdown (shRKIP)) were injected into dorsolateral lobe of prostates of SCID mice ( $n=10 /$ group) and allowed to form tumors for 12 weeks at which time mice were euthanized; lungs excised and metastases quantified as descried in "(e)". Data are reported as the average metastases per sample for 10 mice. ${ }^{*} P<0.05$ versus $p B P$; ${ }^{\#} P<0.05$ versus fRKIP.

suggest that in the basal state, RKIP has minimal impact on apoptosis, but when a stressor is introduced, RKIP has pro-apoptotic effects. In contrast to no impact on endogenous apoptosis, at the 10- and 20 -week time points, there was an increase in the number of proliferative cells found in the non-tumor prostate tissue of the RKIP deficient compared to RKIP intact TRAMP mice. However, this difference was lost by 30 weeks when both groups had tumor present in the prostates. The increased proliferative state of the non-tumor prostate in the RKIP deficient mice could contribute to shorter latency for tumor initiation in these mice. It is unclear why the proliferative rate decreases as the tumors develop; however, this is consistent with a previous report in which the proliferative state of prostate epithelial cells was increased and associated with activation of p38MAPK, JNK, and Erk1.2 during prostate tumor initiation, but was decreased, as was the activation of the signaling molecules, with emergence of poorly differentiated metastatic prostate cancer [30]. As RKIP impacts multiple signaling pathways, it is possible that the overall balance of their activity in the RKIP deficient state results in differential impact on nontumor versus tumor prostate epithelial cells as in the previous report. Along these lines, it is possible that in the RKIP negative background, effects on immune modulatory signaling pathways that RKIP affects, such as NFKB and Stat3, could alter the immune response to tumors allowing for altered tumor proliferation and progression.

Although several studies in a variety of cancer types have shown that overexpression of RKIP in cell lines inhibits metastasis of their xenografts in vivo $[8,31]$, it has not been previously demonstrated that loss of RKIP expression increases metastasis in an in vivo 
model. Our finding that decreased RKIP expression in the TRAMP background increased the metastatic rate suggests that loss of RKIP contributes to metastasis in vivo. However, it does not demonstrate that loss of RKIP alone is sufficient as TRAMP mice readily develop metastasis and thus other changes, in addition to loss of RKIP, may be required for metastasis to occur. Our finding that knockdown of RKIP alone in the LNCaP cells did not enhance their metastatic rate taken together with the observation of increased metastasis in the RKIP deficient TRAMP mice suggests that loss of RKIP alone is insufficient to induce metastasis; however, in the appropriate pro-metastatic context it contributes to the development of metastasis. Furthermore, that restoring RKIP expression in several different cancer types inhibits metastasis, suggests that loss of RKIP is required for metastasis to occur.

\section{CONCLUSIONS}

In summary, we identified that loss of RKIP enhanced the development of metastasis in an autochthonous model of prostate cancer. However, loss of RKIP alone was not sufficient to promote metastasis in a cell line with a low metastatic rate. In light of the previous reports that restoring RKIP expression inhibits metastasis the current findings indicate that the loss of RKIP is necessary but not sufficient to promote prostate cancer metastasis. This finding further supports the important role that RKIP plays in metastasis and provides an additional rationale to explore methods to target RKIP for therapy of prostate cancer to prevent metastasis. Additionally, identification of signaling pathways that cooperate with loss of RKIP to promote metastasis may provide additional therapeutic targets.

\section{REFERENCES}

1. Yeung K, Seitz T, Li S, Janosch P, McFerran B, Kaiser C, Fee F, Katsanakis KD, Rose DW, Mischak H, Sedivy JM, Kolch W. Suppression of Raf-1 kinase activity and MAP kinase signalling by RKIP. Nature 1999;401(6749):173-177.

2. Yousuf $S$, Duan M, Moen EL, Cross-Knorr S, Brilliant $K$, Bonavida B, LaValle T, Yeung KC, Al-Mulla F, Chin E, Chatterjee D. Raf kinase inhibitor protein (RKIP) blocks signal transducer and activator of transcription 3 (STAT3) activation in breast and prostate cancer. PLoS ONE 2014;9(3):e92478.

3. Chatterjee D, Sabo E, Tavares R, Resnick MB. Inverse association between Raf Kinase Inhibitory Protein and signal transducers and activators of transcription 3 expression in gastric adenocarcinoma patients: Implications for clinical outcome. Clin Cancer Res 2008;14(10):2994-3001.

4. Beshir AB, Ren G, Magpusao AN, Barone LM, Yeung KC, Fenteany G. Raf kinase inhibitor protein suppresses nuclear factor-kappaB-dependent cancer cell invasion through negative regulation of matrix metalloproteinase expression. Cancer Lett 2010;299(2):137-149.

5. Klysik J, Theroux SJ, Sedivy JM, Moffit JS, Boekelheide K. Signaling crossroads: The function of Raf kinase inhibitory protein in cancer, the central nervous system and reproduction. Cell Signal 2008;20(1):1-9.

6. Zeng L, Imamoto A, Rosner MR. Raf kinase inhibitory protein (RKIP): A physiological regulator and future therapeutic target. Expert Opin Ther Targets 2008;12(10):1275-1287.

7. George AJ, Holsinger RM, McLean CA, Tan SS, Scott HS, Cardamone T, Cappai R, Masters CL, Li QX. Decreased phosphatidylethanolamine binding protein expression correlates with Abeta accumulation in the $\mathrm{Tg} 2576$ mouse model of Alzheimer's disease. Neurobiol Aging 2006;27(4):614-623.

8. Escara-Wilke J, Yeung K, Keller ET. Raf kinase inhibitor protein (RKIP) in cancer. Cancer Metastasis Rev 2012;31(3-4):615-620.

9. Chatterjee D, Bai Y, Wang Z, Beach S, Mott S, Roy R, Braastad C, Sun Y, Mukhopadhyay A, Aggarwal BB, Darnowski J, Pantazis P, Wyche J, Fu Z, Kitagwa Y, Keller ET, Sedivy JM, Yeung KC. RKIP sensitizes prostate and breast cancer cells to drug-induced apoptosis. J Biol Chem 2004;279(17):17515-17523.

10. Odabaei G, Chatterjee D, Jazirehi AR, Goodglick L, Yeung K, Bonavida B. Raf-1 kinase inhibitor protein: Structure, function, regulation of cell signaling, and pivotal role in apoptosis. Adv Cancer Res 2004;91:169-200.

11. Bonavida B, Jazirehi A, Vega MI, Huerta-Yepez S, Baritaki S. Roles each of Snail, Yin Yang 1 and RKIP in the regulation of tumor cells chemo-immuno-resistance to apoptosis. For Immunopathol Dis Therap 2013;4(1):79-92.

12. Fu Z, Smith PC, Zhang L, Rubin MA, Dunn RL, Yao Z, Keller ET. Effects of raf kinase inhibitor protein expression on suppression of prostate cancer metastasis. J Natl Cancer Inst 2003;95(12): 878-889.

13. Theroux S, Pereira M, Casten KS, Burwell RD, Yeung KC, Sedivy JM, Klysik J. Raf kinase inhibitory protein knockout mice: Expression in the brain and olfaction deficit. Brain Res Bull 2007; 71(6):559-567.

14. Thalmann GNN, Sikes RA, Wu TT, Degeorges A, Chang SM, Ozen M, Pathak S, Chung LW. LNCaP progression model of human prostate cancer: Androgen-independence and osseous metastasis. Prostate 2000;44(2):91-103; Jul 101;144(102).

15. Fu Z, Kitagawa Y, Shen R, Shah R, Mehra R, Rhodes D, Keller PJ, Mizokami A, Dunn R, Chinnaiyan AM, Yao Z, Keller ET. Metastasis suppressor gene Raf kinase inhibitor protein (RKIP) is a novel prognostic marker in prostate cancer. Prostate 2006; 66(3):248-256.

16. Bohl CR, Harihar S, Denning WL, Sharma R, Welch DR. Metastasis suppressors in breast cancers: Mechanistic insights and clinical potential. J Mol Med (Berl) 2014;92(1):13-30.

17. Shoushtari AN, Szmulewitz RZ, Rinker-Schaeffer CW. Metastasis-suppressor genes in clinical practice: Lost in translation? Nat Rev Clin Oncol 2011;8(6):333-342.

18. Dangi-Garimella S, Yun J, Eves EM, Newman M, Erkeland SJ, Hammond SM, Minn AJ, Rosner MR. Raf kinase inhibitory protein suppresses a metastasis signalling cascade involving LIN28 and let-7. EMBO J 2009;28(4):347-358.

19. Greenberg NM, DeMayo F, Finegold MJ, Medina D, Tilley WD, Aspinall JO, Cunha GR, Donjacour AA, Matusik RJ, Rosen JM. Prostate cancer in a transgenic mouse. Proc Natl Acad Sci USA 1995;92(8):3439-3443. 
20. Kaplan-Lefko PJ, Chen TM, Ittmann MM, Barrios RJ, Ayala GE, Huss WJ, Maddison LA, Foster BA, Greenberg NM. Pathobiology of autochthonous prostate cancer in a pre-clinical transgenic mouse model. Prostate 2003;55(3):219-237.

21. Berman-Booty LD, Sargeant AM, Rosol TJ, Rengel RC, Clinton SK, Chen CS, Kulp SK. A review of the existing grading schemes and a proposal for a modified grading scheme for prostatic lesions in TRAMP mice. Toxicol Pathol 2012;40(1):5-17.

22. Ittmann M, Huang J, Radaelli E, Martin P, Signoretti S, Sullivan $\mathrm{R}$, Simons BW, Ward JM, Robinson BD, Chu GC, Loda M, Thomas G, Borowsky A, Cardiff RD. Animal models of human prostate cancer: The consensus report of the New York meeting of the Mouse Models of Human Cancers Consortium Prostate Pathology Committee. Cancer Res 2013;73(9):2718-2736.

23. Marcus DM, Goodman M, Jani AB, Osunkoya AO, Rossi PJ. A comprehensive review of incidence and survival in patients with rare histological variants of prostate cancer in the United States from 1973 to 2008. Prostate Cancer Prostatic Dis 2012;15(3):283-288.

24. Keller ET. Metastasis suppressor genes: A role for raf kinase inhibitor protein (RKIP). Anticancer Drugs 2004;15(7):663-669.

25. Li HZ, Gao Y, Zhao XL, Liu YX, Sun BC, Yang J, Yao Z. Effects of raf kinase inhibitor protein expression on metastasis and progression of human breast cancer. Mol Cancer Res 2009;7(6): 832-840.
26. Li HZ, Wang Y, Gao Y, Shao J, Zhao XL, Deng WM, Liu YX, Yang J, Yao Z. Effects of raf kinase inhibitor protein expression on metastasis and progression of human epithelial ovarian cancer. Mol Cancer Res 2008;6(6):917-928.

27. Cao J, Yan Q. Histone demethylases set the stage for cancer metastasis. Sci Signal 2013;6(273):pe15, 11-12.

28. Valastyan S, Weinberg RA. Tumor metastasis: Molecular insights and evolving paradigms. Cell 2011;147(2):275-292.

29. Wu K, Bonavida B. The activated NF-kappaB-Snail-RKIP circuitry in cancer regulates both the metastatic cascade and resistance to apoptosis by cytotoxic drugs. Crit Rev Immunol 2009;29(3): 241-254.

30. Uzgare AR, Kaplan PJ, Greenberg NM. Differential expression and/or activation of P38MAPK, erk1/2, and jnk during the initiation and progression of prostate cancer. Prostate 2003;55(2): 128-139.

31. Al-Mulla F, Bitar MS, Taqi Z, Yeung KC, RKIP: Much more than Raf kinase inhibitory protein. J Cell Physiol 2013;228(8):1688-1702.

\section{SUPPORTING INFORMATION}

Additional Supporting Information may be found in the online version of this article at the publisher's web-site. 